\title{
Improving hand hygiene compliance in child daycare centres: a randomized controlled trial
}

\author{
T. P. ZOMER ${ }^{1,2} *$, V. ERASMUS ${ }^{2}$, C. W. LOOMAN ${ }^{2}$, E. F. VAN BEECK ${ }^{2}$, \\ A. TJON-A-TSIEN ${ }^{1}$, J. H. RICHARDUS ${ }^{1,2}$ AND H. A. C. M. VOETEN ${ }^{1,2}$ \\ ${ }^{1}$ Department of Infectious Disease Control, Municipal Public Health Service Rotterdam-Rijnmond, Rotterdam, \\ The Netherlands \\ ${ }^{2}$ Department of Public Health, Erasmus MC, University Medical Centre Rotterdam, Rotterdam, The \\ Netherlands
}

Received 4 December 2015; Final revision 19 April 2016; Accepted 21 April 2016; first published online 19 May 2016

\section{SUMMARY}

Gastrointestinal and respiratory infections in children attending daycare centres (DCCs) are common and compliance with hand hygiene $(\mathrm{HH})$ guidelines to prevent infections is generally low. An intervention was developed to increase $\mathrm{HH}$ compliance and reduce infections in DCCs. The objective of this paper was to evaluate the effectiveness of this intervention on $\mathrm{HH}$ compliance. The intervention was evaluated in a two-arm cluster randomized controlled trial in 71 DCCs in The Netherlands. Thirty-six DCCs received the intervention including: (1) HH products; (2) training about HH guidelines; (3) two team training sessions aimed at goal setting and formulating $\mathrm{HH}$ improvement activities; and (4) reminders and cues for action (posters/ stickers). Intervention DCCs were compared to 35 control DCCs that continued usual practice. HH compliance of caregivers and children was observed at baseline and at 1, 3 and 6 months follow-up. Using multilevel logistic regression, odds ratios (ORs) with 95\% confidence intervals (CIs) were obtained for the intervention effect. Of 795 caregivers, $5042 \mathrm{HH}$ opportunities for caregivers and 5606 opportunities for supervising children's HH were observed. At 1 month follow-up caregivers' compliance in intervention DCCs was $66 \%$ vs. $43 \%$ in control DCCs (OR $6 \cdot 33,95 \%$ CI $3 \cdot 71-10 \cdot 80$ ), and at 6 months $59 \%$ vs. 44\% (OR 4.13, 95\% CI 2.33-7.32). No effect of the intervention was found on supervising children's HH (36\%vs. $32 \%$; OR $0 \cdot 64,95 \%$ CI $0 \cdot 18-2 \cdot 33)$. In conclusion, $\mathrm{HH}$ compliance of caregivers increased due to the intervention, therefore dissemination of the intervention can be considered.

Key words: Child daycare, guidelines, hand hygiene, infectious disease control, intervention.

\section{INTRODUCTION}

Attending child daycare centres (DCCs) has been associated with increased risk of acquiring gastrointestinal

\footnotetext{
* Author for correspondence: T. P. Zomer, Department of Infectious Disease Control, Municipal Public Health Service Rotterdam-Rijnmond, PO Box 70032, 3000 LP Rotterdam, The Netherlands.

(Email: tizza.zomer@gmail.com)
}

and respiratory infections [1-3]. These infections can cause parental stress, secondary transmission, healthcare costs, and costs for parental work absence [4-7]. Hand hygiene $(\mathrm{HH})$ is known to be an effective measure to prevent infections $[8,9]$. However, compliance with $\mathrm{HH}$ guidelines in DCCs is generally low [10]. Although several $\mathrm{HH}$ interventions have been developed to reduce infections in children attending DCCs [11-18], these interventions show varying results 
[19] and are not developed according to a stepwise behavioural approach taking into account the determinants that underlie $\mathrm{HH}$ behaviour [20].

Our previous research showed that environmental determinants, such as the availability of paper towels, are associated with caregivers' $\mathrm{HH}$ compliance in DCCs [10]. In addition, we found that the following sociocognitive determinants are associated with HH compliance of DCC caregivers: knowledge and awareness of $\mathrm{HH}$ guidelines, perceived importance of performing $\mathrm{HH}$, perceived behavioural control (i.e. perceived ease or difficulty of performing the behaviour) and habit [21]. We developed an intervention targeting these determinants aiming to increase compliance with $\mathrm{HH}$ guidelines and reduce gastrointestinal and respiratory infections in children attending DCCs. We assessed both HH compliance and incidence of infections as outcome measures. $\mathrm{HH}$ compliance as outcome measure provides insight into a more direct effect of the intervention and might explain the variation in effectiveness of previous $\mathrm{HH}$ intervention studies assessing disease incidence. In this paper we assess the effectiveness of our intervention on improving $\mathrm{HH}$ compliance. The effectiveness on disease incidence is reported separately [22].

\section{METHODS}

A cluster randomized controlled trial of a $\mathrm{HH}$ intervention was performed in DCCs in the regions of Rotterdam-Rijnmond, Gouda and Leiden in The Netherlands between September 2011 and April 2012. DCCs were randomized, stratified for DCC size and urbanicity [23]. In our previous study on determinants of caregivers' HH compliance, 122 DCCs participated $[10,21]$. These DCCs were contacted for participation in the trial. Sample size calculation showed that 35 intervention DCCs and 35 control DCCs were needed [23].

The intervention consisted of four components [23]. First, the following $\mathrm{HH}$ products were provided free of charge with refills for 6 months: dispensers for paper towels, soap, alcohol-based hand sanitizer and hand cream. Second, training was given to educate DCC caregivers about the Dutch national HH guidelines. This included a hand-washing exercise using UV Glow Cream (Deb Benelux Inc.) and an information booklet outlining the content of the training. Third, two team training sessions were given aimed at goal setting and formulating specific
$\mathrm{HH}$ improvement activities. These were based on similar HH training sessions developed for Dutch hospitals [24]. Fourth, reminders and cues for action were provided for both caregivers and children (i.e. posters and stickers). Due to budget restrictions, the $\mathrm{HH}$ products were provided for two groups of the DCC, even if the DCC had more than two groups in total. The other intervention components were provided for all DCC groups and staff members.

Intervention DCCs were compared to control DCCs that continued usual practice. The primary outcome measure was observed $\mathrm{HH}$ compliance of caregivers. Compliance was defined as the number of $\mathrm{HH}$ actions divided by the total number of opportunities for which $\mathrm{HH}$ was indicated. According to Dutch national guidelines, $\mathrm{HH}$ is mandatory for caregivers before touching/preparing food, before caregivers themselves ate or assisted children with eating, and before wound care; and after diapering, after toilet use/wiping buttocks, after caregivers themselves coughed/sneezed/wiped their own nose, after contact with body fluids (e.g. saliva, vomit, urine, blood, or mucus when wiping children's noses), after wound care, and after hands were visibly soiled [25]. For these $\mathrm{HH}$ indications it was observed whether or not $\mathrm{HH}$ was performed. As observations could not take place in the caregivers' lavatory, $\mathrm{HH}$ of caregivers after toilet use was not observed. HH was defined as washing hands with water and soap followed by hand drying, or using an alcohol-based hand sanitizer (which could only be used if hands were not visibly soiled).

Although the primary outcome measure was $\mathrm{HH}$ compliance of caregivers, it was also observed whether caregivers supervised children in washing their hands before eating/preparing food, after toilet use, after playing outside, and after hands were visibly soiled, as indicated in the HH guidelines [25]. Children had to wash their hands with water and soap followed by hand drying. For babies and toddlers who could not wash their hands themselves yet, caregivers could perform HH by using a wet cloth [25].

Compliance was assessed with direct unobtrusive observation by trained observers before the start of the intervention (T0) and 1 (T1), 3 (T3), and 6 (T6) months after start of the intervention. In total, 13 observers were trained aiming for an inter-rater reliability above $75 \%$. Data collection followed phased implementation of the intervention [23]. After observing baseline compliance (T0), intervention DCCs 
received the $\mathrm{HH}$ products, posters/stickers and training regarding the $\mathrm{HH}$ guidelines; after this $\mathrm{HH}$ compliance was observed again (T1), and once more after each of both team training sessions (T3 and T6). At each measurement, the aim was to observe three caregivers for $2 \mathrm{~h}$ in two participating groups per DCC. One observer observed one caregiver at a time, as well as the children under his/her care. Data were collected using the World Health Organization HH observation method [26], adapted for use in child DCCs. At 6 months follow-up, it was also observed whether the dispensers provided as part of the intervention were (still) in use. After the last observations, a survey was conducted among caregivers in intervention DCCs concerning their exposure to the different intervention components.

Data were analysed using SPSS v. 19 (SPSS Inc., USA) and R v. 2.12 .2 (https://cran.r-project.org). Analyses were performed including all intervention DCCs irrespective of whether they used the HH products, posters/stickers or obtained all training sessions (intention-to-treat analyses). First, baseline characteristics were compared. Second, compliance at baseline and total follow-up (T1, T3 and T6 together) was calculated, as well as compliance for the separate follow-up measurements (T1, T3 and T6 separate). For 6 months follow-up (T6), compliance was calculated for each of the $\mathrm{HH}$ indications. Multilevel regression analyses were performed to correct for clustering of the data within DCCs and within caregivers. Using multilevel logistic regression analyses for total follow-up and for each separate follow-up measurement, odds ratios (ORs) with $95 \%$ confidence intervals (CIs) were obtained for the intervention effect (i.e. intervention status of the DCC: intervention vs. control), corrected for confounders that showed significant differences at baseline between intervention and control DCCs. Because the type of activity for which $\mathrm{HH}$ was indicated had previously been shown to be an important determinant of caregivers' $\mathrm{HH}$ [10], this was also included as a confounder. Additional analyses were performed to correct for baseline compliance. For this we calculated the intervention effect as the interaction between intervention status of the DCC (i.e. intervention $v s$. control) and follow-up measurement (i.e. baseline vs. T1, baseline vs. T3, baseline vs. T6, baseline vs. total follow-up).

Ethical approval was waived by the Medical Ethics Committee of the Erasmus University Medical Center in Rotterdam (MEC-2011-256).

\section{RESULTS}

Of 122 DCCs, 71 DCCs participated in the trial (response rate $58 \%$ ). After randomization, there were 36 intervention and 35 control DCCs. At baseline and 1 month after start of the intervention, all 71 DCCs participated. Three months after start of the intervention, one control DDC was lost to follow-up, and 6 months after start of the intervention two more control DCCs were lost to follow-up. In total, 795 caregivers and $5042 \mathrm{HH}$ opportunities were observed. In addition, 5606 opportunities were observed for supervising children's HH. The inter-rater reliability of the observers was $\geqslant 74 \%$.

Comparison of baseline characteristics of intervention and control DCCs demonstrated that in intervention DCCs, age group $(0-1,2-3,0-4$ years) significantly differed from control DCCs (Table 1). This variable was therefore included in further analyses as a confounder. None of the other baseline characteristics were significantly different between intervention and control DCCs (Table 1).

All 36 intervention DDCs received training on $\mathrm{HH}$ guidelines. Of 36 intervention DCCs, two DCCs did not use any of the provided $\mathrm{HH}$ products during the study period. Another two DCCs did not receive any of the team training sessions. At 6 months followup, 94\% (33/35) of intervention DCCs used the paper towel dispensers in at least one of the two groups, $89 \%$ $(31 / 35)$ used the soap dispensers, $86 \%$ (30/35) used the dispensers with alcohol-based hand sanitizer and $45 \%$ $(13 / 29)$ used the dispensers with hand cream. At 6 months follow-up, in 19\% of intervention DCCs (7/ $36)$, neither posters nor stickers of the intervention were used, in $83 \%(29 / 35)$ the posters were used in at least one of two groups, and in $74 \%(26 / 35)$ the stickers were used. The response rate to the questionnaire on exposure to the intervention was $50 \%$ (274/546). Of 274 caregivers, $21 \%(54 / 261)$ attended none of the training sessions, 25\% (66/261) attended one training session, 29\% (75/261) attended two training sessions and $25 \%(66 / 261)$ attended all three sessions. Of 274 caregivers, $77 \%(202 / 262)$ received the information booklet of the training session on $\mathrm{HH}$ guidelines.

\section{HH compliance of caregivers}

Figure 1 shows that caregivers' $\mathrm{HH}$ compliance at baseline was lower in intervention DCCs than in control DCCs. During follow-up, compliance in intervention DCCs was higher than in control DCCs, 
Table 1. Comparison of baseline characteristics $(N=71$ DCCs $)$

\begin{tabular}{|c|c|c|c|}
\hline DCC characteristics & $\begin{array}{l}\text { Intervention DCCs } \\
(N=36)\end{array}$ & $\begin{array}{l}\text { Control DCCs } \\
(N=35)\end{array}$ & $P$ value \\
\hline Size (large, having $\geqslant 46$ children per day) & $53 \%$ & $51 \%$ & $0 \cdot 91$ \\
\hline Degree of urbanicity & & & $0 \cdot 84$ \\
\hline Highly urban & $58 \%$ & $63 \%$ & \\
\hline Urban & $22 \%$ & $23 \%$ & \\
\hline Slightly/non-urban & $19 \%$ & $14 \%$ & \\
\hline \multicolumn{4}{|l|}{ Region } \\
\hline Rotterdam-Rijnmond & $67 \%$ & $66 \%$ & $0 \cdot 47$ \\
\hline Gouda & $14 \%$ & $6 \%$ & \\
\hline Leiden & $19 \%$ & $29 \%$ & \\
\hline Certification (certified) & $44 \%$ & $41 \%$ & $0 \cdot 83$ \\
\hline Age group, years* & & & $0 \cdot 03$ \\
\hline $0-1$ & $21 \%$ & $31 \%$ & \\
\hline $2-3$ & $13 \%$ & $24 \%$ & \\
\hline $0-4$ & $67 \%$ & $44 \%$ & \\
\hline Number of towel facilities for caregivers per group* & $1 \cdot 63$ & 1.54 & $0 \cdot 68 \S$ \\
\hline Type of towel facilities for caregivers in the group* & & & $0 \cdot 14$ \\
\hline Only paper towels & $25 \%$ & $35 \%$ & \\
\hline Only fabric towels & $44 \%$ & $48 \%$ & \\
\hline Both fabric and paper towels & $31 \%$ & $17 \%$ & \\
\hline Number of soap facilities for caregivers per group* & $1 \cdot 55$ & 1.52 & $0.90 \S$ \\
\hline Type of soap facilities for caregivers in the group* & & & 0.66 \\
\hline Only soap dispensers & $14 \%$ & $11 \%$ & \\
\hline Only soap pumps & $70 \%$ & $77 \%$ & \\
\hline Soap dispensers combined with soap pumps & $16 \%$ & $12 \%$ & \\
\hline Alcohol-based hand sanitizer for caregivers in the group (available)* & $67 \%$ & $59 \%$ & $0 \cdot 30$ \\
\hline Number of towel facilities for children per group $\dagger$ & $0 \cdot 98$ & $1 \cdot 00$ & $0.93 \S$ \\
\hline Type of towel facilities for children in the group $\dagger$ & & & $1 \cdot 00$ \\
\hline Only paper towels & $46 \%$ & $46 \%$ & \\
\hline Only fabric towels & $44 \%$ & $44 \%$ & \\
\hline No towel facilities in reach of children & $11 \%$ & $10 \%$ & \\
\hline Number of soap facilities for children per group $\dagger$ & $0 \cdot 84$ & $0 \cdot 75$ & $0 \cdot 62 \S$ \\
\hline Type of soap facilities for children in the group $\dagger$ & & & $0 \cdot 20$ \\
\hline Only soap dispensers & $42 \%$ & $25 \%$ & \\
\hline Only soap pumps & $35 \%$ & $48 \%$ & \\
\hline No soap facilities in reach of children & $23 \%$ & $27 \%$ & \\
\hline Number of children per caregiver: & $5 \cdot 2$ & $5 \cdot 1$ & $0 \cdot 63 \|$ \\
\hline
\end{tabular}

DCC, Daycare centre.

$* N=72$ intervention groups and 70 control groups.

$\dagger N=57$ intervention groups and 48 control groups (groups with children aged 0-2 years were excluded).

$\ddagger N=105$ intervention caregivers and 102 control caregivers.

$\S$ Estimated with Poisson regression.

\| Estimated with independent $t$ test.

although the effect of the intervention seemed to wane slightly.

Compliance at baseline was not significantly different between intervention and control DCCs (respectively $53 \%$ vs. $63 \%$; OR $0.62,95 \%$ CI $0.38-1 \cdot 02$ ) (Table 2). Overall compliance during total follow-up (i.e. taking T1, T3 and T6 together) in intervention DCCs was $62 \%(1243 / 2005)$ vs. $44 \%(812 / 1850)$ in control DCCs. Correcting for type of activity for which $\mathrm{HH}$ was indicated, age group, and clustering of the data within caregivers and within DCCs, the OR was $2 \cdot 69$ (95\% CI $1 \cdot 88-3 \cdot 86)$. The OR was 4.65 (95\% CI 2.99-7.25) when also taking into account baseline compliance. One month after the start of the intervention, compliance in intervention DCCs was $66 \%(459 / 692)$ vs. $43 \%(273 / 640)$ in control DCCs. This difference was significant, correcting for type of activity for which $\mathrm{HH}$ was indicated, age 


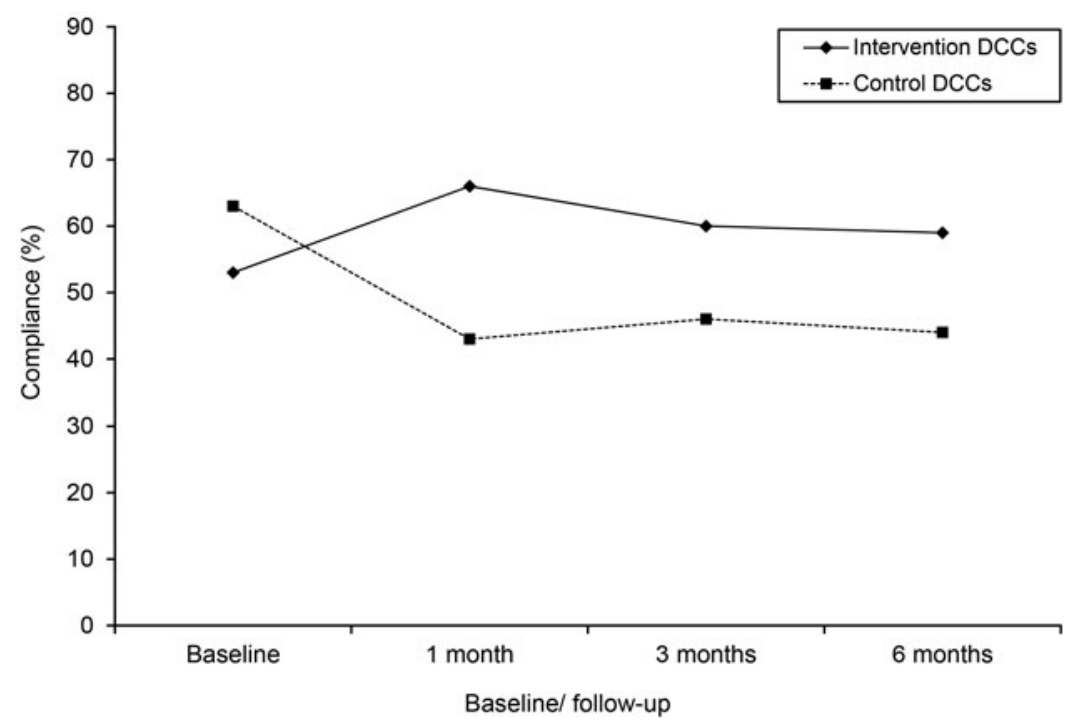

Fig. 1. Effect of the intervention on caregivers' compliance with hand hygiene guidelines in child daycare centres (DCCs) measured at baseline and 1, 3 and 6 months after intervention start.

group, and clustering of the data within caregivers and within DCCs (OR 3.53, 95\% CI 2.23-5.61). Three months after the start of the intervention, compliance was $60 \%(392 / 649)$ in intervention DCCs vs. $46 \%(273 /$ 600 ) in control DCCs (OR 2.45, 95\% CI 1·58-3·80). Six months after the intervention start, compliance in intervention DCCs was 59\% (392/664) vs. 44\% (266/610) in control DCCs (OR 2.49, 95\% CI 1.394.46). When also taking into account baseline compliance the OR for the intervention effect after 6 months was $4 \cdot 13(95 \%$ CI $2 \cdot 33-7 \cdot 32)$.

\section{HH compliance of children}

Children's HH compliance at baseline in intervention DCCs was significantly higher than in control DCCs (respectively, $51 \%$ vs. $38 \%$; OR $4 \cdot 24,95 \%$ CI $1 \cdot 38$ 12.96) (Table 2). Children's compliance during followup (i.e. taking T1, T3 and T6 together) in intervention DCCs was $40 \%(936 / 2362)$ vs. $37 \%(811 / 2183)$ in control DCCs. Corrected for type of activity for which $\mathrm{HH}$ was indicated, age group, and clustering of the data within caregivers and within DCCs, there was no significant difference (OR 1.62, 95\% CI $0 \cdot 77$ $3 \cdot 42$ ). When also taking into account baseline compliance the difference remained non-significant (OR $0 \cdot 78,95 \%$ CI $0 \cdot 25-2 \cdot 44$ ).

Comparison of the different types of activities for which $\mathrm{HH}$ was indicated showed that at 6 months follow-up there was a significant increase in $\mathrm{HH}$ compliance (taking into account baseline) after toilet and diapering activities (OR 4.49, 95\% CI 2.239.05) and after contact with body fluids (OR 4.88, 95\% CI 1.77-13.44) (Table 3). Of toilet and diapering activities, the largest difference in $\mathrm{HH}$ compliance between intervention and control DCCs was $46 \%$ after changing a wet diaper when a child was standing. For activities with body fluid contact, the largest difference was $47 \%$ after caregivers coughed/sneezed/ wiped their own nose (Table 3). The increase in caregivers' $\mathrm{HH}$ compliance before eating and foodhandling activities was not significant (OR 1.95, 95\% CI 0.76-5.00) (Table 3).

\section{DISCUSSION}

This is the first HH intervention in DCCs developed according to a stepwise behavioural approach targeting the underlying determinants of caregivers' compliance with $\mathrm{HH}$ guidelines. To our knowledge, this is also the first study to assess HH compliance of caregivers as primary outcome measure, as well as children's HH compliance. Our study demonstrates that the intervention we developed for DCCs is effective in improving caregivers' compliance with $\mathrm{HH}$ guidelines.

Most HH intervention studies in DCCs report as outcome measure the incidence of gastrointestinal and/or respiratory infections, and/or absence of caregivers/children due to illness [11-18]. Although most of these studies show a reduced rate of infection associated with the implementation of the intervention 
Table 2. Effect of the intervention on compliance with hand hygiene ( $H H$ ) guidelines in child daycare centres (DCCs) measured at baseline and 1,3 and 6 months after start of the intervention

\begin{tabular}{|c|c|c|c|c|c|c|c|c|c|c|c|}
\hline $\begin{array}{l}\text { Baseline/ } \\
\text { follow-up }\end{array}$ & $\begin{array}{l}\text { Intervention } \\
\text { status of the } \\
\text { DCC }\end{array}$ & $\begin{array}{l}\text { No. of } \\
\text { DCCs }\end{array}$ & $\begin{array}{l}\text { No. of } \\
\text { caregivers } \\
\text { observed }\end{array}$ & $\begin{array}{l}\text { No. of } \mathrm{HH} \\
\text { opportunities } \\
\text { for caregivers }\end{array}$ & $\begin{array}{l}\text { Compliance } \\
\text { of caregivers } \\
(\%)\end{array}$ & $\begin{array}{l}\text { OR* } \\
(95 \% \mathrm{CI})\end{array}$ & $\begin{array}{l}\text { Baseline } \\
\text { corrected } \\
\text { OR } \dagger(95 \% \mathrm{CI})\end{array}$ & $\begin{array}{l}\text { No. of } \mathrm{HH} \\
\text { opportunities } \\
\text { for children }\end{array}$ & $\begin{array}{l}\text { Compliance of } \\
\text { children }(\%)\end{array}$ & $\begin{array}{l}\text { OR* } \\
(95 \% \mathrm{CI})\end{array}$ & $\begin{array}{l}\text { Baseline } \\
\text { corrected } \\
\text { OR } \dagger \\
(95 \% \mathrm{CI})\end{array}$ \\
\hline \multirow[t]{2}{*}{ Baseline } & Intervention & 36 & 105 & 623 & 53 & $\begin{array}{l}0 \cdot 62 \\
(0 \cdot 38-1 \cdot 02)\end{array}$ & - & 583 & 51 & $\begin{array}{l}4 \cdot 24 \\
(1 \cdot 38-12 \cdot 96)\end{array}$ & - \\
\hline & Control & 35 & 102 & 564 & 63 & Ref. & & 478 & 38 & Ref. & \\
\hline \multirow[t]{2}{*}{$\begin{array}{l}1 \text { month } \\
\text { follow-up }\end{array}$} & Intervention & 36 & 105 & 692 & 66 & $\begin{array}{l}3 \cdot 53 \\
(2 \cdot 23-5 \cdot 61)\end{array}$ & $\begin{array}{l}6 \cdot 33 \\
(3 \cdot 71-10 \cdot 80)\end{array}$ & 738 & 39 & $\begin{array}{l}1 \cdot 31 \\
(0 \cdot 38-4 \cdot 60)\end{array}$ & $\begin{array}{l}0 \cdot 30 \\
(0 \cdot 08-1 \cdot 16)\end{array}$ \\
\hline & Control & 35 & 97 & 640 & 43 & Ref. & Ref. & 637 & 42 & Ref. & Ref. \\
\hline \multirow[t]{2}{*}{$\begin{array}{l}3 \text { months } \\
\text { follow-up }\end{array}$} & Intervention & 36 & 101 & 649 & 60 & $\begin{array}{l}2 \cdot 45 \\
(1 \cdot 58-3 \cdot 80)\end{array}$ & $\begin{array}{l}4 \cdot 08 \\
(2 \cdot 37-7 \cdot 02)\end{array}$ & 770 & 44 & $\begin{array}{l}1 \cdot 40 \\
(0.54-3.63)\end{array}$ & $\begin{array}{l}0 \cdot 83 \\
(0 \cdot 20-3 \cdot 38)\end{array}$ \\
\hline & Control & 34 & 97 & 600 & 46 & Ref. & Ref. & 841 & 39 & Ref. & Ref. \\
\hline \multirow[t]{2}{*}{$\begin{array}{l}6 \text { months } \\
\text { follow-up }\end{array}$} & Intervention & 36 & 99 & 664 & 59 & $\begin{array}{l}2 \cdot 49 \\
(1 \cdot 39-4 \cdot 46)\end{array}$ & $\begin{array}{l}4 \cdot 13 \\
(2 \cdot 33-7 \cdot 32)\end{array}$ & 854 & 36 & $\begin{array}{l}3 \cdot 03 \\
(1 \cdot 02-9 \cdot 03)\end{array}$ & $\begin{array}{l}0.64 \\
(0 \cdot 18-2 \cdot 33)\end{array}$ \\
\hline & Control & 32 & 89 & 610 & 44 & Ref. & Ref. & 705 & 32 & Ref. & Ref. \\
\hline \multirow[t]{2}{*}{$\begin{array}{l}\text { Total } \\
\text { follow-up }\end{array}$} & Intervention & 36 & 305 & 2005 & 62 & $\begin{array}{l}2 \cdot 69 \\
(1 \cdot 88-3 \cdot 86)\end{array}$ & $\begin{array}{l}4 \cdot 65 \\
(2 \cdot 99-7 \cdot 25)\end{array}$ & 2362 & 40 & $\begin{array}{l}1 \cdot 62 \\
(0 \cdot 77-3 \cdot 42)\end{array}$ & $\begin{array}{l}0 \cdot 78 \\
(0 \cdot 25-2 \cdot 44)\end{array}$ \\
\hline & Control & 35 & 283 & 1850 & 44 & Ref. & Ref. & 2183 & 37 & Ref. & Ref. \\
\hline
\end{tabular}

OR, Odds ratio; CI, confidence interval.

* Difference between intervention and control DCCs corrected for the type of activities for which HH was indicated, age group (i.e. 0-1, 2-3 and 0-4 years), and clustering of the data within caregivers and within DCCs.

$\dagger$ Interaction effect of intervention status of the DCC and baseline/follow-up measurement corrected for the type of activities for which HH was indicated, age group (i.e. 0-1,

2-3 and 0-4 years), and clustering of the data within caregivers and within DCCs. 
Table 3. Effect of the intervention on the compliance with each specific hand hygiene ( $H H$ ) indication outlined in the Dutch national guidelines for child daycare centres (DCCs), measured at baseline and 6 months after start of the intervention

\begin{tabular}{|c|c|c|c|c|c|c|c|c|}
\hline & \multicolumn{4}{|c|}{$\begin{array}{l}\text { Follow-up compliance at } \\
6 \text { months }\end{array}$} & \multirow{3}{*}{$\begin{array}{l}\text { Difference } \\
(\%)\end{array}$} & \multirow{3}{*}{$\begin{array}{l}\text { Baseline } \\
\text { corrected } \\
\text { difference* } \\
(\%)\end{array}$} & \multirow{2}{*}{\multicolumn{2}{|c|}{$\begin{array}{l}\text { Baseline } \\
\text { corrected } \dagger\end{array}$}} \\
\hline & \multicolumn{2}{|c|}{$\begin{array}{l}\text { Intervention } \\
\text { DCCs }\end{array}$} & \multicolumn{2}{|c|}{$\begin{array}{l}\text { Control } \\
\text { DCCs }\end{array}$} & & & & \\
\hline & $\%$ & (n) & $\%$ & (n) & & & OR & $95 \% \mathrm{CI}$ \\
\hline Overall compliance caregivers & 59 & (664) & 44 & (610) & 15 & 25 & $4 \cdot 13$ & $2 \cdot 33-7 \cdot 32$ \\
\hline Eating/food handling & 39 & (196) & 24 & (164) & 15 & 14 & 1.95 & $0 \cdot 76-5 \cdot 00$ \\
\hline Before food handling & 51 & (111) & 29 & (83) & 22 & 25 & & \\
\hline Before caregivers themselves ate & 19 & (26) & 20 & (35) & -1 & 8 & & \\
\hline Before caregivers assisted children with eating & 25 & (59) & 20 & (46) & 5 & -19 & & \\
\hline Toilet/diapering & 73 & (322) & 57 & (272) & 16 & 28 & $4 \cdot 49$ & $2 \cdot 23-9 \cdot 05$ \\
\hline After changing a diaper with faeces & 94 & (77) & 80 & (71) & 14 & 20 & & \\
\hline $\begin{array}{l}\text { After changing a wet diaper when child was } \\
\text { lying down }\end{array}$ & 69 & (144) & 56 & (127) & 13 & 26 & & \\
\hline $\begin{array}{l}\text { After changing a wet diaper when child was } \\
\text { standing }\end{array}$ & 56 & (79) & 31 & $(65)$ & 25 & 46 & & \\
\hline $\begin{array}{l}\text { After wiping buttocks when assisting children } \\
\text { with toilet use }\end{array}$ & 82 & (22) & 78 & (9) & 4 & -6 & & \\
\hline Contact with body fluids & 55 & (105) & 38 & (127) & 17 & 35 & $4 \cdot 88$ & $1 \cdot 77-13 \cdot 44$ \\
\hline $\begin{array}{l}\text { After caregivers coughed/sneezed/wiped their } \\
\text { own nose }\end{array}$ & 42 & (24) & 23 & (22) & 19 & 47 & & \\
\hline After contact with body fluids & 60 & (75) & 39 & (99) & 21 & 39 & & \\
\hline Before wound care & 33 & (3) & 33 & (3) & n.a. & n.a. & & \\
\hline After wound care & 67 & (3) & 100 & (3) & n.a. & n.a. & & \\
\hline After visibly soiled hands & 59 & (41) & 49 & (47) & 10 & 11 & $2 \cdot 11$ & $0 \cdot 13-34 \cdot 22$ \\
\hline Overall compliance children & 38 & (605) & 41 & (475) & -3 & -16 & $0 \cdot 64$ & $0 \cdot 18-2 \cdot 33$ \\
\hline Before eating & 18 & (275) & 18 & (195) & 0 & -1 & & \\
\hline Before food handling & 0 & (5) & 100 & (6) & n.a. & n.a. & & \\
\hline After toilet use & 48 & (95) & 48 & (101) & 0 & -5 & & \\
\hline After playing outside & 75 & (81) & 46 & (48) & 29 & 3 & & \\
\hline After visibly soiled hands & 48 & (149) & 66 & (125) & -18 & -52 & & \\
\hline
\end{tabular}

OR, Odds ratio; CI, confidence interval.; n.a., not applicable (as activities occurred $\leqslant 5$ times).

* Difference between intervention and control DCCs at 6 months follow-up minus the difference at baseline.

$\dagger$ Interaction effect of intervention status of the DCC and baseline/follow-up measurement corrected for the type of activities for which $\mathrm{HH}$ was indicated, age group (i.e. $0-1,2-3$ and $0-4$ years), and clustering of the data within caregivers and within DCCs.

programme, the nature and magnitude of the effect varies (e.g. the effect is not present for both gastrointestinal and respiratory infections) [19]. Insight into a more direct effect of the intervention, namely $\mathrm{HH}$ compliance, might explain this, as possibly $\mathrm{HH}$ compliance only improved for certain $\mathrm{HH}$ indications (e.g. diapering $v s$. nose wiping).

There are few studies to compare our results with. One other DCC intervention study assessed observed $\mathrm{HH}$ compliance of caregivers as outcome measure, although no comparison with control DCCs was reported [16]. That study reports that after training, caregivers' $\mathrm{HH}$ improved after diapering and after contact with mucus, saliva, vomit, etc. of children [16]. In our study, HH also improved after toilet and diapering activities and after contact with body fluids. The improvement of caregivers' HH after contact with body fluids might be explained by the provision of alcohol-based hand sanitizer which made it possible for caregivers to perform $\mathrm{HH}$ after wiping children's noses, e.g. when they were playing outside as some DDCs placed the dispensers by the outdoor storage shed. No effect was found on $\mathrm{HH}$ compliance before eating and food-handling activities. Therefore, intervention studies for improving $\mathrm{HH}$ compliance in DCCs should pay special attention to these activities. 
Another study assessed children's HH behaviour [12]. At 6 months follow-up, the adjusted relative risk for $\mathrm{HH}$ before lunch was 2.93 (95\% CI 1.86-6.97) and after bathroom use it was 3.30 (95\% CI 1.83-16.67) [12]. In two other studies, only compliance of children in intervention DCCs was reported, and no information was given on compliance in control DCCs or at baseline $[14,15,18]$. In our study, we did not find an effect on children's HH compliance. This might be explained by the fact that our intervention primarily focused on caregivers and was developed based on determinants of caregivers' $\mathrm{HH}$ behaviour and not children's HH behaviour. Besides the posters and stickers, our intervention did not include components specifically targeting children (e.g. hand-washing songs). Furthermore, our study shows that improving $\mathrm{HH}$ compliance of caregivers does not automatically yield improving compliance in supervising children's HH. Determinants of (supervising) children's HH might therefore be different from determinants of caregivers' $\mathrm{HH}$ and studies are needed to assess these.

Prior to intervention development, we assessed caregivers' $\mathrm{HH}$ compliance in DCCs and showed that the overall compliance was $42 \%$ [10]. Although compliance was higher at baseline (i.e. 53\% in intervention DCCs and 63\% in control DCCs), compliance in control DCCs during follow-up was similar, with little variation over time $(43 \%$ at $\mathrm{T} 1,46 \%$ at $\mathrm{T} 3$, $44 \%$ at T6). Because baseline measurement thus seems to be an outlier, especially for control DCCs, we report results both uncorrected and corrected for baseline compliance. At baseline the incidence of gastrointestinal infections was also higher in control DCCs compared to intervention DCCs, which dropped during follow-up [22]. This might explain the high $\mathrm{HH}$ compliance in control DCCs at baseline, as our previous qualitative study showed that caregivers usually increase their $\mathrm{HH}$ when observing diarrhoea in the children (T. P. Zomer et al., unpublished data).

A strength of our study is that $\mathrm{HH}$ compliance of both caregivers and children was observed and that besides overall compliance, the compliance for each of the specific $\mathrm{HH}$ indications is also reported. Furthermore, our intervention had multiple components, addressing environmental and sociocognitive determinants of HH. Moreover, exposure to the different intervention components was high, except for the hand cream dispensers that were delivered halfway through the intervention period (because during the team training sessions it became clear that there was a need for hand cream dispensers to reduce sore and dry hands). Other strengths of the study are the randomized controlled design, the high inter-rater reliability among observers, and the large sample size of 71 participating DCCs and 795 observed caregivers. In addition, control DCCs also received the intervention after data collection, which probably facilitated DCC recruitment and minimized loss to follow-up [12].

A possible limitation of our study is the Hawthorne effect; caregivers might change their behaviour when they know they are being observed [27]. Although this bias could not be entirely prevented, it was minimized by observing unobtrusively and by informing caregivers that the focus of the observations was on hygiene in general, not specifically mentioning HH. In addition, the physical appearance of the observers was similar to that of caregivers working in the DCCs, as most of them were young females. Furthermore, repeated exposure to observations could make caregivers less sensitive to adapting their behaviour during observations [26]. Nevertheless, we would expect the Hawthorne effect to be more pronounced in intervention DCCs than in control DCCs, as being exposed to the intervention made it more likely for caregivers to know the purpose of the observation. The intervention effect might then be an overestimation of the true effect size. The incidence of gastrointestinal and respiratory infections in children attending DCCs [22] would then be a more objective outcome measure. Another possible limitation is that observers might have recognized the intervention status of the DCC, which could have biased data collection. Furthermore, children's HH compliance was only assessed in children for which the observed caregiver was responsible, and not in all children in the group. Better assessment of children's HH compliance would include all the children. Another possible limitation is that the participating DCCs also participated in our previous study on determinants of $\mathrm{HH}$ behaviour, for which they received information regarding their $\mathrm{HH}$ compliance 6 months prior to intervention start. Therefore, the intervention effect might be an underestimation of the true effect size.

In conclusion, this study shows that our intervention, addressing determinants that underlie caregivers' $\mathrm{HH}$ behaviour, is effective in improving caregivers' $\mathrm{HH}$ compliance in DCCs. Therefore, dissemination of the intervention in other DCCs can be considered (especially when determinants of $\mathrm{HH}$ behaviour are 
similar). DCCs can then implement the intervention to distinguish themselves from a quality perspective from other DCCs. More studies are needed to assess the duration of the intervention effect beyond 6 months and to assess which components of the intervention are most effective.

\section{ACKNOWLEDGEMENTS}

We thank Jitske de Graaf (Erasmus MC) and Elise van Beeck (Erasmus MC) for administrative support and data collection. The study was by funded by the Netherlands Organization for Health Research and Development (ZonMw), project number 125020 006. Dispensers and refills were sponsored by SCA Hygiene Products, Sweden. [Trial registration: Dutch trials registry NTR3000.]

\section{DECLARATION OF INTEREST}

None.

\section{REFERENCES}

1. Nafstad P, et al. Day care centers and respiratory health. Pediatrics 1999; 103: 753-758.

2. Barros H, Lunet N. Association between child-care and acute diarrhea: a study in Portuguese children. Revista de Saude Publica 2003; 37: 603-608.

3. Barros AJ. Child-care attendance and common morbidity: evidence of association in the literature and questions of design. Revista de Saude Publica 1999; 33: 98-106.

4. Van der Wielen M, et al. Impact of community-acquired paediatric rotavirus gastroenteritis on family life: data from the REVEAL study. BMC Family Practice 2010; 11: 22.

5. Lee MB, Greig JD. A review of enteric outbreaks in child care centers: effective infection control recommendations. Journal of Environmental Health 2008; 71: 24-32.

6. Silverstein M, Sales AE, Koepsell TD. Health care utilization and expenditures associated with child care attendance: a nationally representative sample. Pediatrics 2003; 111: e371-e375.

7. Giaquinto $\mathbf{C}$, et al. Costs of community-acquired pediatric rotavirus gastroenteritis in 7 European countries: the REVEAL Study. Journal of Infectious Diseases 2007; 195: S36-S44.

8. Ejemot RI, et al. Hand washing for preventing diarrhoea. Cochrane Database of Systematic Reviews 2008. Art. no. CD004265. Issue no. 1.

9. Jefferson T, et al. Physical interventions to interrupt or reduce the spread of respiratory viruses. Cochrane Database of Systematic Reviews 2011. Art. no. CD006207. Issue no. 7.

10. Zomer TP, et al. Hand hygiene compliance and environmental determinants in child day care centers: An observational study. American Journal of Infection Control 2013; 41: 497-502.

11. Gudnason T, et al. Does hygiene intervention at day care centres reduce infectious illnesses in children? An intervention cohort study. Scandinavian Journal of Infectious Diseases 2013; 45: 397-403.

12. Rosen $\mathbf{L}$, et al. Can a handwashing intervention make a difference? Results from a randomized controlled trial in Jerusalem preschools. Preventive Medicine 2006; 42: 27-32.

13. Ponka A, Poussa T, Laosmaa M. The effect of enhanced hygiene practices on absences due to infectious diseases among children in day care centers in Helsinki. Infection 2004; 32: 2-7.

14. Roberts L, et al. Effect of infection control measures on the frequency of diarrheal episodes in child care: a randomized, controlled trial. Pediatrics 2000; 105: 743-746.

15. Roberts L, et al. Effect of infection control measures on the frequency of upper respiratory infection in child care: a randomized, controlled trial. Pediatrics 2000; 105: 738-742.

16. Kotch JB, et al. Evaluation of an hygienic intervention in child day-care centers. Pediatrics 1994; 94: 991-994.

17. Kotch JB, et al. Hand-washing and diapering equipment reduces disease among children in out-of-home child care centers. Pediatrics 2007; 120: e29-e36.

18. Uhari M, Mottonen M. An open randomized controlled trial of infection prevention in child day-care centers. Pediatric Infectious Disease Journal 1999; 18: 672-677.

19. Huskins WC. Transmission and control of infections in out-of-home child care. Pediatric Infectious Disease Journal 2000; 19: S106-S110.

20. Bartholomew LK, et al. Planning Health Promotion Programs: An Intervention Mapping Approach. San Francisco: Jossey-Bass, 2011.

21. Zomer TP, et al. Sociocognitive determinants of observed and self-reported compliance to hand hygiene guidelines in child day care centers. American Journal of Infection Control 2013; 41: 862-867.

22. Zomer TP. et al. A hand hygiene intervention to reduce infections in child daycare: a randomized controlled trial. Epidemiology and Infection 2015; 143: 2494-2502.

23. Zomer TP, et al. A hand hygiene intervention to decrease infections among children attending day care centers: design of a cluster randomized controlled trial. BMC Infectious Diseases 2013; 13: 259.

24. Huis A, et al. Impact of a team and leaders-directed strategy to improve nurses' adherence to hand hygiene guidelines: A cluster randomised trial. International Journal of Nursing Studies 2013; 50: 464-474.

25. Dutch National Institute for Public Health and the Environment (RIVM), Dutch National Centre for Hygiene and Safety (LCHV). Health risks in a child daycare centre or preschool (0 to 4 year olds) [in Dutch]. Bilthoven, The Netherlands. July 2011.

26. Sax H, et al. The World Health Organization hand hygiene observation method. American Journal of Infection Control 2009; 37: 827-834.

27. Pan SC, et al. Compliance of health care workers with hand hygiene practices: independent advantages of overt and covert observers. PLOS ONE 2013; 8: e53746. 